\title{
Impact of environmental factors on in situ determination of iron in seawater by flow injection analysis
}

\author{
Agathe Laës ${ }^{a}$, Renaud Vuillemin ${ }^{b}$, Bernard Leilde $^{b}$, Géraldine Sarthou $^{a}$, \\ Claudie Bournot-Marec ${ }^{c}$ and Stéphane Blain ${ }^{d}$
}

\author{
${ }^{a}$ Institut Universitaire Européen de la Mer, LEMAR UMR CNRS 6539, Place Nicolas Copernic, 29280 Plouzané, \\ France \\ ${ }^{b_{I}}$ IFREMER Centre de Brest TMSI/TSI BP 70, 29280 Plouzané, France \\ 'INSU/CNRS, IFRTP BP74, Technopôle Brest-Iroise, 29280 Plouzané, France \\ ${ }^{d}$ Centre d'Océanologie de Marseille, LOB UMR CNRS 6535, campus de Luminy, case 901, F-13288 Marseille \\ Cedex, France \\ *: Corresponding author : Tel.: +33 2984986 67; fax: +33 2984986 45. Agathe.Laes@univ-brest.fr
}

\begin{abstract}
A sensitive method for iron determination in seawater has been adapted on a submersible chemical analyser for in situ measurements. The technique is based on flow injection analysis (FIA) coupled with spectrophotometric detection. When direct injection of seawater was used, the detection limit was $1.6 \mathrm{nM}$, and the precision $7 \%$, for a triplicate injection of a $4 \mathrm{nM}$ standard. At low iron concentrations, on line preconcentration using a column filled with 8-hydroxyquinoline (8HQ) resin was used. The detection limit was $0.15 \mathrm{nM}$ (time of preconcentration $=240 \mathrm{~s}$ ), and the precision $6 \%$, for a triplicate determination of a $1 \mathrm{nM}$ standard, allowing the determination of $\mathrm{Fe}$ in most of the oceanic regimes, except the most depleted surface waters. The effect of temperature, pressure, salinity, copper, manganese, and iron speciation on the response of the analyser was investigated. The slope of the calibration curves followed a linear relation as a function of pressure $(\mathrm{Cp}=2.8 \times 10-5 \mathrm{P}+3.4 \times$ 10- $2 \mathrm{~s} \mathrm{nmol}-1, \mathrm{R} 2=0.997$, for $\Theta=13^{\circ} \mathrm{C}$ ) and an exponential relation as a function of temperature $(\mathrm{C} \Theta=0.009 \mathrm{e} 0.103 \Theta, \mathrm{R} 2=0.832$, for $\mathrm{P}=3$ bar $)$. No statistical difference at $95 \%$ confidence level was observed for samples of different salinities $(S=0,20,35)$. Only very high concentration of copper $(1000 \times[\mathrm{Fe}])$ produced a detectable interference. The chemical analyser was deployed in the coastal environment of the Bay of Brest to investigate the effect of iron speciation on the response of the analyser. Direct injection was used and seawater samples were acidified on line for $80 \mathrm{~s}$. Dissolved iron (DFe, filtered seawater $(0.4 \mu \mathrm{m})$, acidified and stored at pH 1.8) corresponded to $29 \pm 4 \%$ of Fea (unfiltered seawater, acidified in line at $\mathrm{pH} 1.8$ for $80 \mathrm{~s}$ ). Most of Fea $(71 \pm 4 \%$ ) was probably a fraction of total dissolvable iron (TDFe, unfiltered seawater, acidified and stored at $\mathrm{pH} 1.8$ ).
\end{abstract}

Keywords: Flow injection analysis; Iron; In situ measurements; Seawater; Submersible chemical analyser; Temperature and pressure effects 


\section{1- Introduction}

In situ chemical analysis in seawater is actually one of the most difficult and fascinating challenge facing marine analytical chemists. Since the pioneer works on the in situ measurement of conductivity to determine salinity, large progress has been made in electronics, mechanics, data storage and processing. Today the development of new in situ chemical measurements is mainly limited by the finding of appropriate processes which convert concentrations of chemical species into a physical signal. In situ chemical measurements are based on two different approaches: Passive sensors use passive transport of the chemical species in seawater to the detector, whereas chemical analysers use active transport of seawater through a detector (Blain et al., 2000). Sensor approach is very attractive because it requires a simplified technology compared to the chemical analyser. However, few chemical sensors have been really used in situ (oxygen, Riemers and Glud, 2000), and nitrate, Johnson and Coletti, 2002). Most of the in situ chemical measurements have been performed using chemical analysers. The methods associated to these submersible analysers are generally based on Continuous Flow Analysis (CFA) or on Flow Injection Analysis (FIA). Trace metals in-situ analysis is a very interesting approach because sampling and subsequent processing of the sample, which are possible sources of contamination, are eliminated. Iron in situ analysis have already been reported in the literature but in environments with iron concentrations higher than those encountered in the open ocean (Coale et al., 1991, Chin et al., 1994, Gamo et al., 1994, Massoth et al., 1995, Chapin et al., 2002). These methods are validated in laboratory in quite stable and controlled environmental conditions (temperature, pressure) and with well operationally defined speciation of samples (e.g. filtered, acidified). During in situ deployment of chemical analysers, most of the environmental factors, which largely vary in the water column, are not under control. Therefore it is critical to determine their impact on the chemistry. Several studies have reported the variation in sensitivity of the chemical reaction as a function of temperature and pressure (Johnson et al., 1986a; Gamo et al., 1994; Daniel et al., 1995a; Floch et al., 1998; Sarradin et al., 1999; Le Bris et al., 2000; Okamura et al., 2001; Weeks and Bruland, 2002). The sensitivity varies with the nature of the chemical reaction and with the technical components of the analyser. We report here the results for the adaptation of a sensitive method for iron determination in seawater (Measures et al., 1995) to a submersible chemical analyser. We investigated the effect of temperature, pressure, reagents and standards, salinity, copper and manganese on the response of the analyser. Finally, we compared in situ measurements obtained by the chemical analyser to laboratory sample treatment and analysis.

\section{2-Material and methods}

\section{1-The submersible chemical analyser}

The submersible chemical analyser used in our study has already been described in details in previous papers (Daniel et al., 1995a; Daniel et al., 1995b; Floch et al., 1998). It can be deployed until $6000 \mathrm{~m}$ for continuous measurements ( 8 hours). Briefly the manifold (Fig. 1) consisted of an 8 channel peristaltic pump (P, Minipulse MPII, Gilson) and 2 Upchurch valves (injection V2 and selection V1), controlled by a motor located in oil-pressure compensated container. The temperature of a small reaction coil $(3.96 \mathrm{~cm})$ was set up using a thermostated oil bath up to $35^{\circ} \mathrm{C}$. The flow cell was made of quartz (path length $\mathrm{L}=30 \mathrm{~mm}$ 
and internal diameter $\mathrm{ID}=1 \mathrm{~mm})$. Light absorption was measured at two different wavelengths (540 and $810 \mathrm{~nm})$. The sampling rate was $1 \mathrm{~Hz}$.

\section{2- Reagents}

In order to avoid any contamination, standard, sample, and reagent preparation was performed under a class 100 laminar flow hood, according to trace metal clean techniques (Bruland et al., 1979). All solutions were prepared with MilliQ (MQ, ${ }^{\circledR}$ Millipore MilliQ water system) with @Suprapur reagents, and were stored in precleaned low density polyethylene bottles (LDPE). The carrier was made by dilution of $15.2 \mathrm{ml}$ of chlorydric acid ( $\mathrm{HCl},{ }^{\circledR}$ Suprapur Merck) into one litre of filtered seawater with low iron concentration (below $0.15 \mathrm{nM}$ ) collected in the Southern Atlantic Ocean (Bowie et al., 2003). The hydrogen peroxide solution $\left(\mathrm{H}_{2} \mathrm{O}_{2}, 5 \%\right)$ was obtained by dilution of $167 \mathrm{ml}$ of hydrogen peroxide $30 \%$ (®Suprapur Merck) into one litre of MQ water. Ammonium acetate buffer was prepared by dilution of $115 \mathrm{ml}$ acetic acid (99.9\% for analysis, Carlo Erba Reagenti) and $130 \mathrm{ml}$ of ammonia $25 \%\left(\mathrm{NH}_{4} \mathrm{OH}\right.$, ®Suprapur Merck) into one litre of MQ water. The $\mathrm{pH}$ was adjusted to 6.2 by addition of the appropriated reagent, acetic acid or ammonia. Finally $1.5 \mathrm{ml}$ of Brij-35 (15\%, Fluka Biochemica) and $5.34 \mathrm{ml}$ of triethylenetetramine (0.013 M, Fluka Chemica) were added to the buffer. The solution of N,N-dimethyl-pphenylenediamine (4-amino-N,N-dimethylaniline) dihydrochloride (DPD) was prepared daily to avoid any degradation. $0.962 \mathrm{~g}$ of DPD (Fluka Chemica) was dissolved into $100 \mathrm{ml}$ of MQ water to obtain the final concentration of $0.046 \mathrm{M}$. The sample buffer solution $(0.5$ $\mathrm{M} ; \mathrm{pH}=4.5$ ) was made by dissolution of $10.25 \mathrm{~g}$ of sodium acetate $99.99 \%$ (囚Suprapur Merck) and $6.6 \mathrm{ml}$ of $\mathrm{HCl} 30 \%$ (®Ultrapur Merck) into $250 \mathrm{ml}$ of MQ. The standards were prepared by diluting iron standard solution of $1 \mathrm{mg} \mathrm{l}^{-1}$ for AAS (Carlo Erba Reagenti) into acidified filtered low iron sea water.

\section{3-FIA manifold}

To avoid any Fe contamination, the system was leached with weak $\mathrm{HCl}\left({ }^{\circledR}\right.$ suprapur Merck, $0.4 \mathrm{M}$ ) for few hours, before and after every experiment.

\subsection{1- In line purification of the reagents}

The mixture of DPD and ammonium acetate buffer was purified in line using a hydroxyquinoline resin (Dierssen et al., 2001), 8HQ column, L=75 mm, ID=2 mm, Fig. 1). For in situ application, reagents and standards were placed in acid-precleaned plastic bags (Baxter Fenwall). These plastic bags were made with chemically inert ethylene vinyl acetate film. After cleaning, the concentration of DFe in MQ water contained in the plastic bags was below the limit of detection. 
Figure 1: FIA manifolds a- For direct injection of sample, b- For preconcentration of sample, V1: 6 port selection valve, V2: 6 port injection valve, P: peristaltic pump, 1: 8HQ column for reagents purification, 2: sample loop for direct injection, 2': 8HQ column for iron preconcentration, 3: insulated oil bath with reaction loop, 4: flow cell, S white lamp, D dualwavelength detector $(810 \mathrm{~nm} ; 540 \mathrm{~nm})$, All the tubing was made of Teflon (Upchurch ID $0.8 \mathrm{~mm}$ ), except pump tubing which were made of tygon (VWR). The connections were made of PEEK (Upchurch). The length of the thermostated reaction loop was 96.
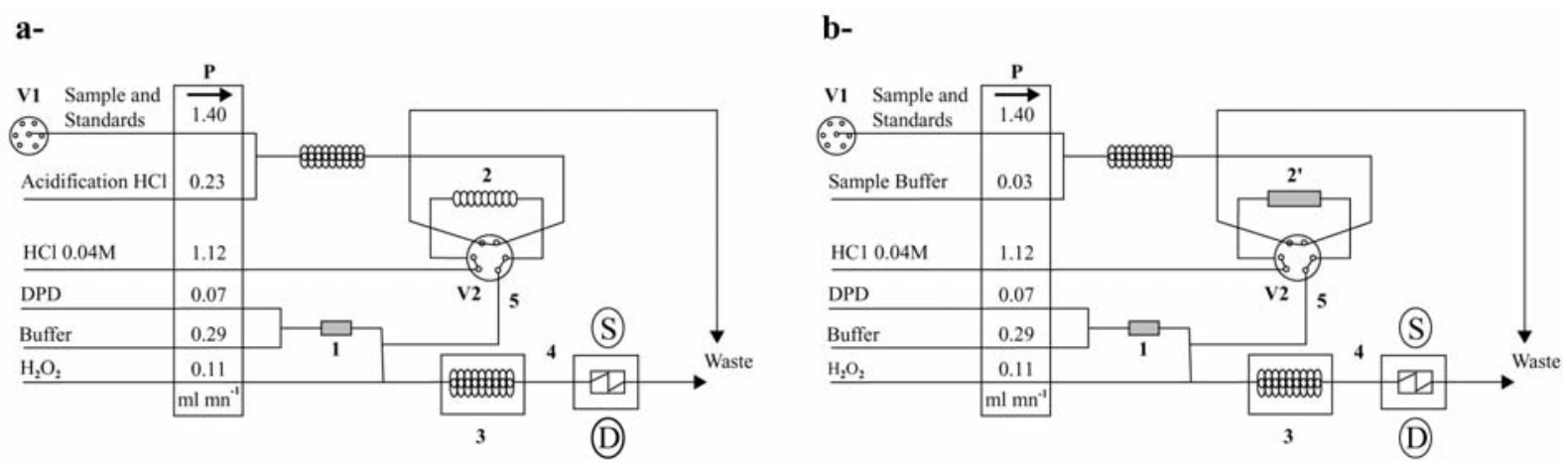

\subsection{2- In line acidification for direct injection of samples}

In line acidification of the sample was implanted into the manifold (Fig. 1a). The $\mathrm{HCl}$ solution (600 $\mu 1$ of $\mathrm{HCl}$ (®Ultrapur Merck) in 60ml of MQ water) was pumped at $0.23 \mathrm{ml}$ $\mathrm{min}^{-1}$ and mixed with standard (acidified by $500 \mu \mathrm{HCl}{ }^{\circledR}$ Ultrapur Merck in $500 \mathrm{ml}, \mathrm{pH}=2$ ) or sample, both pumped at $2.0 \mathrm{ml} \mathrm{min}^{-1}$. The time of acidification was $80 \mathrm{~s}$, resulting in a final $\mathrm{pH}$ of 1.8. The $\mathrm{pH}$ was checked after mixing of seawater with the acidification reagent. The acidified sample passed then through the injection loop.

\subsection{3- In line preconcentration of samples}

In order to decrease the detection limit, a manifold with in line preconcentration was implemented on the analyser (Fig. 1b). An 8HQ preconcentration column ( $\mathrm{L}=12 \mathrm{~mm}$, $\mathrm{ID}=2 \mathrm{~mm}$ ) was used. The sample buffer was mixed with the sample at a flow rate of $0.03 \mathrm{ml} \mathrm{min}^{-1}$ to obtain a final $\mathrm{pH}$ of 4.7 . The $\mathrm{pH}$ of the acidified standards was adjusted to $\mathrm{pH} 4.7$ by additions of $\mathrm{NH}_{3} 25 \%$ (®Suprapur Merck) and $1 \%$ of the sample buffer. The standards were then stored in plastic bags for in situ analysis.

\subsection{4- Manifold for chemical reaction}

The carrier and cleaned buffer/DPD mixture combined with $\mathrm{H}_{2} \mathrm{O}_{2}$ and the overall stream was driven to the thermostat, where the reaction could be carried on at controlled temperature during $50 \mathrm{~s}$. The $\mathrm{pH}$ of the final reaction was checked after mixing with the various reagents $(\mathrm{pH}=6.1)$.

\section{4- Blank correction}

The analytical blank is composed of two fractions: the contribution of the reagents and the contribution of the FIA manifold.

The contribution of the $\mathrm{HCl}, \mathrm{NH}_{3}$ and buffer addition to the blank was investigated by standard addition of each reagent in low iron seawater. Their contribution to the blank was below the limit of detection $(\mathrm{LD}=0.15 \mathrm{nM})$. 
For the FIA manifold contribution there are two different cases with preconcentration and with in line acidification.

Preconcentration:

The contribution of the FIA manifold was estimated using different times of preconcentration (40-100s) and by extrapolating the signal to a preconcentration time equal to zero. The contribution of the manifold was then subtracted from the standard and the samples integral values.

Direct injection of seawater:

The manifold contribution should be obtained by extrapolating the sample loop volume to zero. However it was impossible to change, in situ, the volume of the sample loop. Then, each time the analyser was deployed, 10 replicates of the standard zero were recorded before starting the calibration. We used low iron seawater ([Dfe] $=40 \mathrm{pM})$ below the limit of detection $(\mathrm{LD}=1.6 \mathrm{nM})$. The mean of ten replicates gave the blank which was subtracted from the sample integral.

\section{5- Signal treatment}

The reference signal (Fig. 2a), was measured at a wavelength outside the reaction product absorbance spectrum $(810 \mathrm{~nm})$. The sample signal was measured at the wavelength corresponding to the maximum of absorption of the reaction product $(540 \mathrm{~nm})$. This allows correcting from the variation of the refractive index. The final absorbance (Fig. 2b) was computed via dual wavelength treatment, using the following equation (Daniel et al., 1995b):

$$
A=\log \left[k \int_{t=0}^{60} R(t) d t / \int_{t=0}^{60} S(t) d t\right]
$$

$\mathrm{k}=\mathrm{i}_{\mathrm{S}} / \mathrm{i}_{\mathrm{r}} \cdot \mathrm{i}_{\mathrm{s}}$ and $\mathrm{i}_{\mathrm{r}}$ are the baselines at 810 and $540 \mathrm{~nm}$ respectively. $\mathrm{R}(\mathrm{t})$ and $\mathrm{S}(\mathrm{t})$ are the absorbances at 810 and $540 \mathrm{~nm}$ respectively. Only the positive parts of the absorbance signal were integrated. The final integral I resulted from the integration over time of A, once corrected from negative values.

\section{6- Deployment at sea}

The chemical submersible analyser was used at sea in the Bay of Brest $\left(48^{\circ} 19^{\prime} 121 \mathrm{~N}\right.$, 4³1'326 W), on board N/O Côtes de la Manche (29-30 October 2003). It was mounted on a rosette and associated with a CTD probe (Seabird, SBE 19+) measuring in situ salinity, temperature and oxygen concentration. As relatively high iron concentrations were expected in this area, measurements were done using direct injection of seawater. $\mathrm{Fe}_{\mathrm{a}}$, determined in situ by the analyser, corresponded to the fraction of iron of an unfiltered sample which was acidified at $\mathrm{pH} 1.8$ during $80 \mathrm{~s}$. At the beginning of the cast, the rosette was immersed close to the bottom $(25 \mathrm{~m})$ for an in situ calibration. A typical analysis (triplicate of an injection of a standard or a sample) was performed within 12 minutes. In order to better define this operationally in situ sample treatment, unfiltered and filtered seawater was also sampled for later analysis in the laboratory. Unfiltered samples collected thanks to the acid precleaned Niskin bottles, were acidified at $\mathrm{pH} 1.8$ ( $\mathrm{HCl} \circledR$ ultrapur Merck) and stored in precleaned LDPE bottles for determination of total dissolvable iron (TDFe) concentrations. Samples from the Niskin bottles were also filtered $(0.4 \mu \mathrm{m})$, acidified at $\mathrm{pH} 1.8$ ( $\mathrm{HCl}$ ®ultrapur Merck) and stored in LDPE bottles for dissolved iron (DFe) determination. The acidified samples (DFe and TDFe) were analysed one week later 
in the laboratory using FIA with chemiluminescence detection (Laës et al., 2003) adapted from (Obata et al., 1993).

Figure 2: a- Voltage as a function of time at both detectors (black: $810 \mathrm{~nm}$, grey $540 \mathrm{~nm}$ ), DFe concentration in seawater was of $2 \mathrm{nM}$,

b- Corrected (grey) and non corrected absorbance (black) as a function of time, DFe concentration in seawater was $3 \mathrm{nM}$ (See text for details of the calculation)

a -

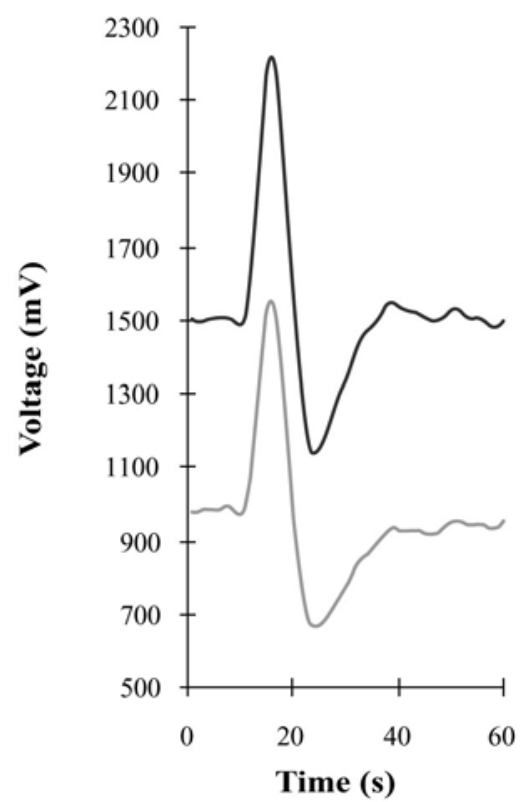

b -

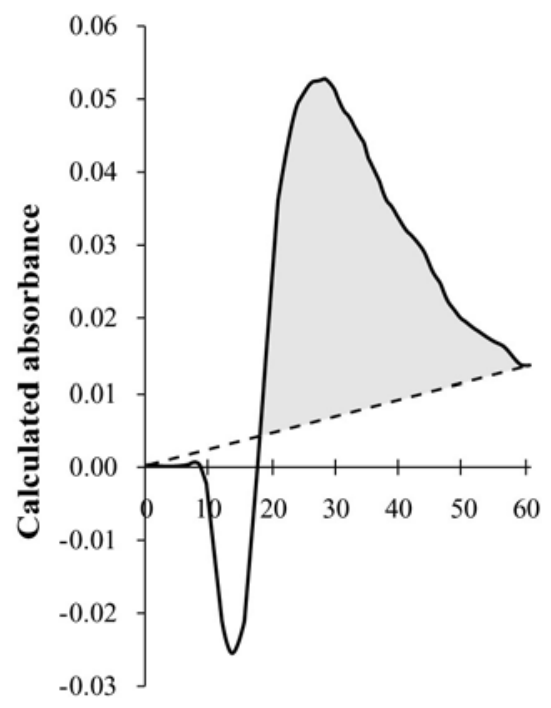

Time (s)

\section{3-Results and discussion}

\subsection{Figures of merits of the method}

\subsection{1- Direct injection of seawater}

First, we investigated the effect of the carrier flow rate. Three flow rates: 1.12, 0.70 and $0.42 \mathrm{ml} \mathrm{min}^{-1}$ were studied (Fig. 3). During these experiments, the $\mathrm{pH}$ of the reaction was maintained at a constant value by adjusting the concentration of the carrier $(\mathrm{HCl})$. The height of the signal increased as the flow rate decreased, because the lower the flow rate, the more complete the chemical reaction. The width of the peak also increased as the flow rate decreased, therefore the signal could only be properly integrated with a flow rate of $1.12 \mathrm{ml} \mathrm{min} \mathrm{m}^{-1}$. It was chosen for all other investigations. The effect of the volume of injection loop was also investigated within the range $175 \mu 1$ to $682 \mu \mathrm{L}$. Integrated absorbance varied linearly with the injection volume until concentrations reached $100 \mathrm{nM}$. The largest injection loop $(682 \mu \mathrm{l})$ was used to obtain best the sensitivity. The figure of merits of the method, linearity, detection limit, accuracy and precision are summarised in Table 1. The broad range (from 0 to $100 \mathrm{nM}$ ) where the response is linear, as well as the low detection limit $(1.60 \mathrm{nM})$ permit the use of the submersible chemical analyser in different type of natural aquatic environments: rivers, estuaries, and coastal areas. The 
accuracy of the method was assessed by analysing the certified reference material NASS-5. Results were not statistically different from the certified value at a confidence level of $95 \%$.

Table 1: Figures of merit of the methods

Analytical parameters

Slope of the calibration curve $\left(\mathrm{snmol}^{-1}\right)$

Intercept of the calibration curve (s)

Regression coefficient

Range of linearity (nM)

Detection limit (nM)

Precision $(\%)$

Accuracy (NASS-5 (nM)) (d)
Direct injection

$\begin{array}{ll}810^{-2} \pm 2.10^{-2} & 2010^{-2} \pm 4.10^{-2} \\ 1.15 \pm 0.28 & 0.42 \pm 0.33 \\ 0.991(\mathrm{n}=18) & 0.996(\mathrm{n}=11) \\ 0-100 & 0-64 \\ 1.60 & 0.15(\mathrm{a}) \\ 7(\mathrm{~b}) & 6(\mathrm{c}) \\ 3.65 \pm 0.25 & \mathbf{3 . 5 6} \pm \mathbf{0 . 1 8}\end{array}$

(a) Preconcentration time of $240 \mathrm{~s}$.

(b) Determined for a standard of $4 \mathrm{nM}$

(c) Determined for a standard of $1 \mathrm{nM}$

(d) Certified value: $3.70 \pm 0.63 \mathrm{nM}$

Figure 3: Influence of carrier flow rate (open circles: $0.42 \mathrm{ml} \mathrm{min}{ }^{-1}$, filled diamonds: $0.70 \mathrm{ml} \mathrm{min}^{-1}$, filled squares: $1.12 \mathrm{ml} \mathrm{min}^{-1}$ ). DFe concentration in seawater was $35 \mathrm{nM}$

\subsection{2-}

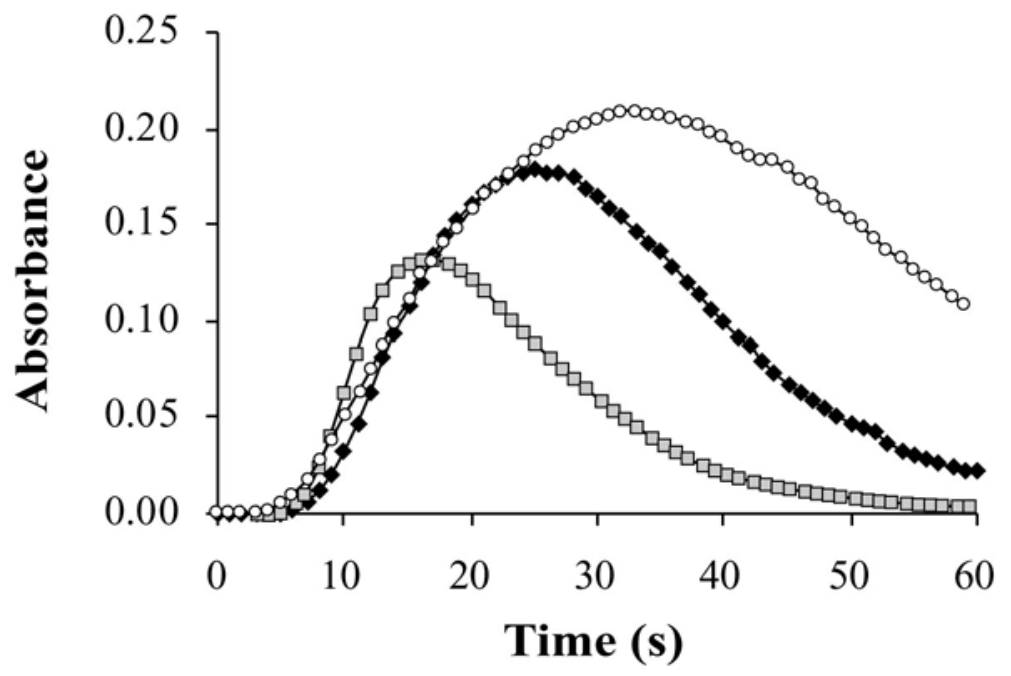

\section{Preconcentration step}

The detection limit of the method using direct injection of seawater was not low enough to measure Fe concentrations in other ocean areas than coastal ones. Preconcentration step has been largely used to improve the limit of detection of the FIA methods dedicated to trace metal measurement. One of the most common methods used in line preconcentration on a small column filled with chelating resin (e.g. 8 hydroxy quinolein linked to various resin, (Dierssen et al., 2001). The retention of ferrous and ferric ions on the resin is highly dependent on the $\mathrm{pH}$ of the sample. During an intercalibration exercise, Bowie et al. (2003) showed that the various methods use a preconcentration $\mathrm{pH}$ ranged between 4.5 and 5 . The chemiluminescence method used to make the comparison with the in situ method tested 
here also preconcentrates at $\mathrm{pH}$ 4.7. That is why we decide to use 4.7 for preconcentration in that study. The iron concentrations of the buffered standards were constant over 6 hours. The figures of merits of the method are summarised in Table 1. Using a preconcentration time of $240 \mathrm{~s}$, the detection limit was $0.15 \mathrm{nM}$. The wide range of concentration where the response is linear, as well as the good accuracy allow the determination of $\mathrm{Fe}$ in most of the oceanic regimes, excepted the most depleted surface waters.

\subsection{Impact of environmental factors on the chemical reaction}

\subsection{1- Temperature and pressure}

When profiles are performed from surface to deep waters temperature and pressure can vary over large range. These variations can modify the chemical reaction rate. Several studies have reported a decrease in sensitivity with a lowering temperature (Johnson et al., 1986a; Gamo et al., 1994;Floch et al., 1998; Okamura et al., 2001). Weeks and Bruland, (2002) reported, for the same colorimetric method as the one used in this study, that the effect of raising the temperature by $12{ }^{\circ} \mathrm{C}$ alone, accounted for a doubling of the sensitivity. Inversely, other investigations observed an increase in sensitivity as the temperature decreased (Sarradin et al., 1999; Le Bris et al., 2000). Daniel et al., (1995a) did not observe any variation of the integrated signal between 10 and $20{ }^{\circ} \mathrm{C}$. Pressure increase generally enhances the sensitivity of the method (Johnson et al., 1986a; Gamo et al., 1994; Le Bris et al., 2000). But it can also have negative effects on the sensitivity (Okamura et al., 2001). The temperature and the pressure variations depend on the nature of the chemical method. We wanted to test the temperature and the pressure effect, not only on the chemical reaction itself as performed by Weeks and Bruland, (2002), but on the whole system including instrumental components, reagents and standards. We achieved such experiments using a hyperbaric testing tank (IFREMER, Brest) in which the pressure could be raised up to 1000 bars and the temperature decreased from ambient temperature down to $2^{\circ} \mathrm{C}$.

In a preliminary experiment, the temperature in the hyperbaric testing tank was maintained between 9.5 and $11.5^{\circ} \mathrm{C}$ and a constant pressure of 3 bars was applied to the analyser. Two calibrations were performed with direct injection of seawater. The first calibration was achieved without any regulation of the temperature of the reaction loop. The slope of the calibration curve was $0.023 \pm 0.001 \mathrm{snmol}^{-1}$. The second calibration was obtained with a temperature regulation of the reaction loop at $20^{\circ} \mathrm{C}$. In that case, the slope increased by a factor of two $\left(0.047 \pm 0.011 \mathrm{snmol}^{-1}\right)$, whereas the precision dramatically decreased (from $4 \%$ to $23 \%$ ). This is due to a lack of precision of the temperature regulation. When the oil bath reached the set temperature, the heating was automatically switched off. But due to the inertia of the system, the temperature was still increasing for one or two degrees. Therefore, the effect of the variation of ambient temperature (from 5 to $15.5{ }^{\circ} \mathrm{C}$ ) was investigated without thermostat regulation and at a constant pressure of 3 bars. The integral I increased exponentially as a function of the temperature: for $20 \mathrm{nM} \mathrm{I}=0.182 \mathrm{e}^{0.106 \Theta}, \mathrm{R}^{2}=0.857$, for 10 $\mathrm{nM} \mathrm{I}=0.101 \mathrm{e}^{0.096 \Theta}, \mathrm{R}^{2}=0.705$. The standard zero integrals at 5,8 and $11{ }^{\circ} \mathrm{C}$ are statistically equivalent (confidence interval of $95 \%$ ). We also observed an exponential increase of the slope $\left(C_{\Theta}\right)$ of the calibration curve $C_{\Theta}=0.009 \mathrm{e}^{0.103 \Theta}, \mathrm{R}^{2}=0.832$ (Fig $\left.4 \mathrm{~b}\right)$. 
Figure 4: a- Relationship between integral $(\mathrm{I})$ and temperature $(\Theta)$ (black triangles: $20 \mathrm{nM} \mathrm{I}=0.182 \mathrm{e}^{0.106 \Theta}$, $\mathrm{R}^{2}=0.857$; grey diamonds: $10 \mathrm{nM} \mathrm{I}=0.101 \mathrm{e}^{0.096 \Theta}, \mathrm{R}^{2}=0.705$; open diamonds: standard zero, no specific trend) b- Relationships between calibration curve $\left(\mathbf{C}_{\boldsymbol{\Theta}}\right)$ and temperature $(\Theta)\left(\mathbf{C}_{\Theta}=0.009 \mathrm{e}^{0.103 \Theta}, \mathrm{R}^{2}=0.832\right)$
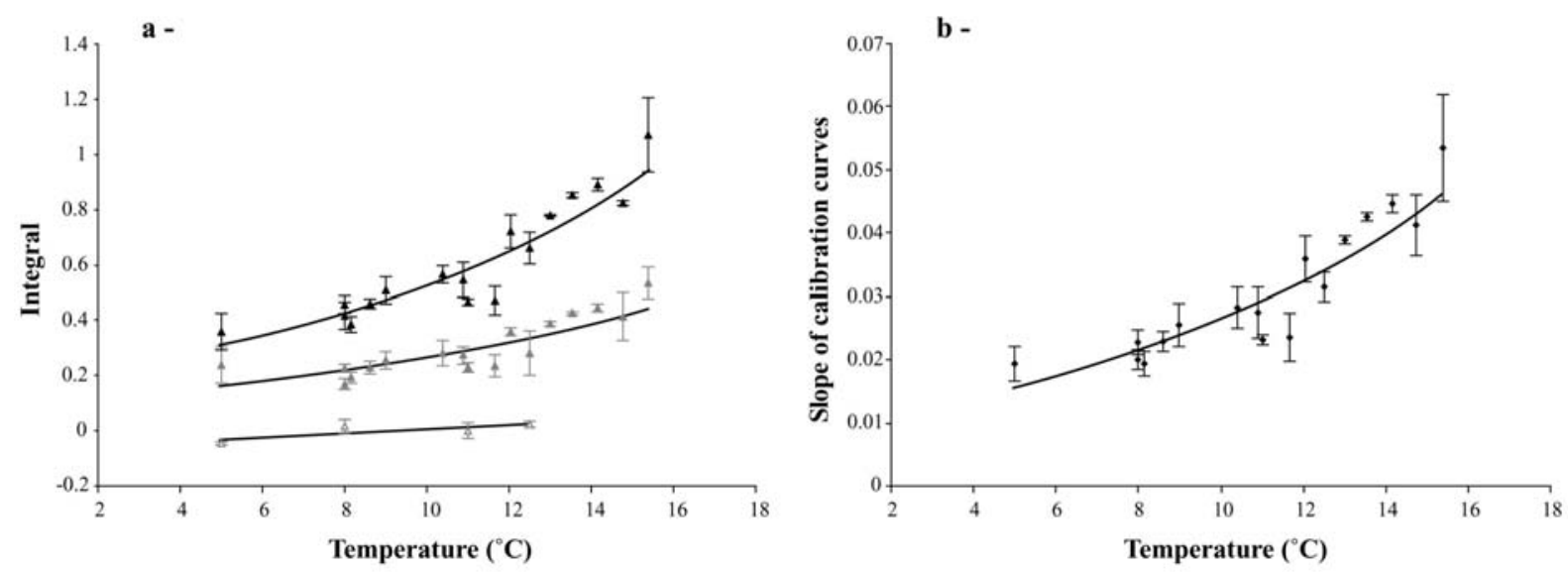

In order to better understand the effect of temperature, the shape of the signal was examined. The height $(\mathrm{H})$ of the peak of absorbance A decreased when temperature increased (Fig. 5a). In the same time, the width of the peak at half height $\left(\mathrm{W}_{1 / 2}\right)$ increased (Fig. 5b). This peak broadening can be due to physical factors (variation in flow rate or mixing), or to chemical factors (reaction rate). The signal at $810 \mathrm{~nm}$ provides information on the physical factors alone, as it is not influenced by the reaction coloration. The time at which the maximum of the peak at $810 \mathrm{~nm}$ appeared was delayed as temperature increased. An average delay of $1.16 \mathrm{~s}$ was recorded for an increase of $11^{\circ} \mathrm{C}$. The change in the properties of the pump tubing (elasticity, inner diameter) could be at the origin of this delay. Some additional tests were made showing no significant variation in the flow rate for a solution of MilliQ between $5^{\circ} \mathrm{C}$ and $24{ }^{\circ} \mathrm{C}\left(24^{\circ} \mathrm{C}: 1.89 \pm 0.01 \mathrm{mlmin}^{-1}, 5^{\circ} \mathrm{C}: 1.85 \pm 0.04\right.$ $\mathrm{mlmin}^{-1}$ ). Therefore we conclude that if change of properties of pump tubing occurred with temperature variation, these changes are weak, and do not impact significantly the flow rate. However, some significant variations were observed for the same conditions with a seawater. The flow rates $\left(2.02 \pm 0.06 \mathrm{mlmin}^{-1}\right.$ at $24^{\circ} \mathrm{C}$ and $1.85 \pm 0.03 \mathrm{mlmin}^{-1}$ at $5^{\circ} \mathrm{C}$ : $)$ were significantly different. This new result support the hypothesis of Daniel et al. (1995): variations of the viscosity of seawater with temperature cause changes in flow rate. As the temperature rises, the viscosity of the fluid decreases, leading to a higher flow rate. Consequently, when the temperature was low, the chemical reaction had more time to develop before the sample entered the detector. This is visible on Fig.5a. An increase in viscosity, when $\Theta$ is lowered, could also lead to an increase in diffusion and consequently to a decrease in $\mathrm{W}_{1 / 2}$ (peak spreading). Fig. 5b illustrates this hypothesis. However, if the variations in the flow rate were the unique factors controlling the variation of the signal at $810 \mathrm{~nm}$, we would expect an increase of A when temperature decreased. Fig. 4a shows the opposite trend. In fact, temperature also controls the rate of the chemical reaction. The rate of this catalytic based reaction is controlled by the Arrhenius equation (Weeks and Bruland, 2002). Using our data, we plotted $C_{\Theta}=f\left(e^{-1 / \Theta}\right)$ giving $C_{\Theta}=0.061 \mathrm{e}^{-7.540 / \Theta}, R^{2}=0.560$. Low $R^{2}$ value indicates that Arrhenius law cannot explain all the observed variations of $C_{\Theta}$. This is consistent with the impact of physical factors on $\Theta$ as explained above. Physical (viscosity) and chemical (Arrhenius law) parameters are both at the origin of the chemical rate variation. 
Figure 5: a- Height of absorbance signal as a function of temperature (black squares: $20 \mathrm{nM}$; grey squares: 10 nM; open squares: blank)

b- Width at half height of the absorbance signal as a function of temperature
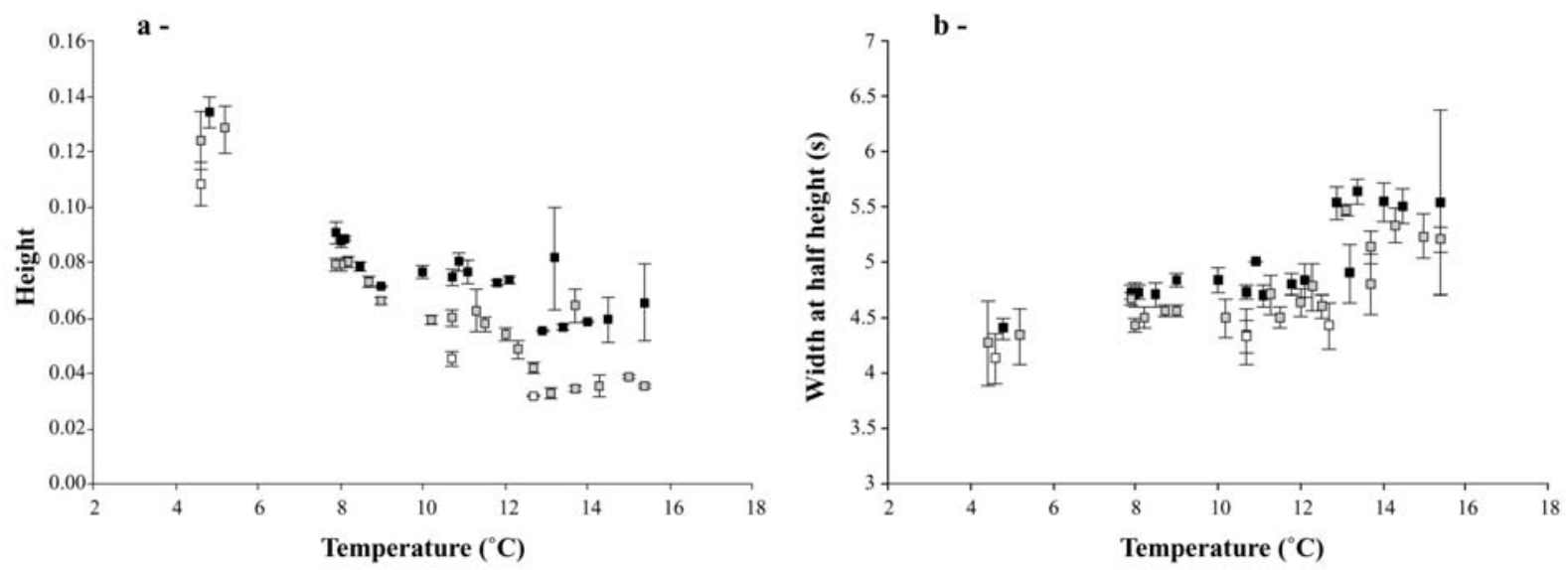

The pressure effect was investigated at $13{ }^{\circ} \mathrm{C}$ using the following pressures: $3,100,200$, 300 and 400 bars. The slope of the calibration curves $\left(\mathrm{C}_{\mathrm{p}}\right)$ obtained at different pressures was plotted as a function of pressure. $C_{p}$ varied linearly with the pressure: $C_{p}=2.8 \cdot 10^{-5}$ $\mathrm{P}+3.4 .10^{-2} \mathrm{~s} \mathrm{nmol}^{-1}, \mathrm{R}^{2}=0.997$. The maximum of the signal at $810 \mathrm{~nm}$ was delayed with higher pressure. This might be due to a squeezing effect of the pump tubing. This indicates that the flow rate decreased with increase in pressure. Table 2 summarises the parameters of the linear regression obtained at various pressures. The positive slopes of $C_{3}, C_{100}, C_{200}$, $\mathrm{C}_{300}$, and $\mathrm{C}_{400}$ are consistent with the expected impact of a reduction of the flow rate on the chemical reaction (see above section).

Table 2: Parameters of the linear regression: slope of the calibration curve (C) and intercept $\left(\mathrm{Y}_{0}\right)$ of the equation $\mathrm{I}=\mathrm{CpP}+\mathrm{Y}_{0}$ as a function of pressure $(\mathrm{P})$

\begin{tabular}{lllllll}
$\begin{array}{l}\text { Pressure } \\
\text { (bar) }\end{array}$ & $\begin{array}{l}\mathrm{C} \\
\left(\mathrm{s} \mathrm{nmol}^{-1}\right)\end{array}$ & $\begin{array}{l}\text { Standard } \\
\text { deviation } \\
\text { of C }\end{array}$ & $\mathrm{Y}_{0}(\mathrm{~s})$ & $\begin{array}{l}\text { Standard } \\
\text { deviation } \\
\text { of } \mathrm{Y}_{0}\end{array}$ & $\begin{array}{l}\text { Regression } \\
\text { coefficient }\end{array}$ & $\begin{array}{l}\text { Number of } \\
\text { points }\end{array}$ \\
\hline & & & & & & \\
3 & 0.034 & 0.002 & 0.349 & 0.057 & 0.967 & 9 \\
100 & 0.036 & 0.001 & 0.339 & 0.021 & 0.996 & 9 \\
200 & 0.040 & 0.005 & 0.471 & 0.116 & 0.909 & 9 \\
300 & 0.042 & 0.005 & 0.476 & 0.116 & 0.918 & 9 \\
400 & 0.045 & 0.002 & 0.555 & 0.050 & 0.985 & 9
\end{tabular}

Our results showed that this in situ analysis is highly sensitive to changes in temperature and pressure. Significant relationships exist between $\mathrm{C}$, temperature and pressure. However, we have determined these equations at a specific temperature of $13^{\circ} \mathrm{C}$ for the pressure study, and 3 bars for the temperature study. These equations do not allow to correct for simultaneous changes in temperature and pressure. If variations of pressure larger than 2 
bars and temperature larger than $1{ }^{\circ} \mathrm{C}$, occur simultaneously, the only way to get an accurate in situ measurement of the iron concentrations is to calibrate in situ the analyser at this specific depth, and this specific temperature.

\subsection{2- Salinity and chemical interferences}

The effect of salinity on A was examined using 3 standards $(20 \mathrm{nM})$ with different salinities: 35, 20 and 0 . No statistical difference at 95\% confidence level (Fisher test, $n=7$; $\mathrm{P}=0.0345$ ) was observed. Therefore calibration run in seawater can be used to study samples with lower salinity. Interference experiments were conducted in seawater containing $35 \mathrm{nM}$ of iron. Copper and manganese, metals supposed to induce interference, were added at concentrations 10,100, 1000 times higher than iron concentration. Similarly to Measures et al. (1995), we found that only very high concentration of copper (1000 x $[\mathrm{Fe}])$ produced a detectable interference. The method can then be considered as free of $\mathrm{Cu}$ and $\mathrm{Mn}$ interferences.

\subsection{3- Speciation}

The chemical analyser was used at sea in the Bay of Brest. The profiles of salinity $\left(\mathrm{S}_{\text {mean }}=35.420 \pm 0.004\right)$, temperature $\left(\Theta_{\text {mean }}=13.447 \pm 0.005{ }^{\circ} \mathrm{C}\right)$ and oxygen $\left(\left[\mathrm{O}_{2}\right]_{\text {mean }}=297.67 \pm 0.89 \mu \mathrm{molkg}^{-1}\right)$ showed that the water column was well mixed. Calibration was performed at a shallow depth of $25 \mathrm{~m}$, and no correction was applied for pressure and temperature. $\mathrm{Fe}_{\mathrm{a}}$ corresponds to the fraction of iron of an unfiltered sample which has been acidified at $\mathrm{pH} 1.8$ during $80 \mathrm{~s}$. $\mathrm{Fe}_{\mathrm{a}}$ profile (Fig. 6) showed a mid depth maximum around $12.5 \mathrm{~m}(20.7 \mathrm{nM})$. The lowest concentrations $(16.5 \mathrm{nM})$ were observed at $4 \mathrm{~m}$, at $24 \mathrm{~m}$ the $\mathrm{Fe}_{\mathrm{a}}$ concentrations were $17.4 \mathrm{nM}$. DFe concentrations were filtered seawater $(0.4 \mu \mathrm{m})$, acidified at $\mathrm{pH} 1.8$ and stored during one week. DFe profiles (4.5-5.7 $\mathrm{nM}$ ) displayed similar trend, except close to the bottom where an increase in DFe was observed $(5.7 \mathrm{nM})$. TDFe were analysed from unfiltered samples acidified at $\mathrm{pH} 1.8(\mathrm{HCl}$ (Rultrapur Merck) and stored in precleaned LDPE bottles during one week. TDFe concentrations were very high and roughly constant from 4 to $17 \mathrm{~m}(162 \pm 17 \mathrm{nM})$, but significantly decreased close to the bottom $(141 \mathrm{nM})$. The concentrations of DFe measured in the Bay are usual for coastal environments (de Baar and de Jong 2001). The high TDFe concentrations are consistent with the occurrence of large amount of particles, biogenic or lithogenic, in the bay. Concentrations of Fea were always higher than DFe, but much lower than TDFe. Our results show that the operationally defined fraction of Fe measured by the analyser was significantly different from the two other fractions DFe and TDFe. Clearly the contribution of $\mathrm{DFe}$ to $\mathrm{Fe}_{\mathrm{a}}$ is small. If we assume that all $\mathrm{DFe}$ is included in Fea, DFe contributes for only $29 \pm 4 \%$ of $\mathrm{Fe}_{\mathrm{a}}$. Most of $\mathrm{Fe}_{\mathrm{a}}(71 \pm 4 \%$ of $\mathrm{TDFe})$ was probably a fraction of easily leachable particulate iron. Obata et al., (1997) reported that at $\mathrm{pH} 3.2$, there was no significant difference in TDFe between suspensions that were acidified for more than $6 \mathrm{~h}$ and those that stood for only 1-2 min. Our results are really different from data of Obata et al., (1997). In fact, difference in sample treatment makes the comparison between operationally defined fractions of Fe not possible. Future utilisation of the in situ chemical analyser for comparison of $\mathrm{Fe}_{\mathrm{a}}$ determined by in line acidification will require to define standard protocols and intercalibration exercise. 
Figure 6: Comparison of iron profiles obtained by the in situ analyser (grey diamonds: Fea), deployed in the Bay of Brest, with the profiles of dissolved iron (open triangles: DFe) and total dissolvable iron (black squares: TDFe) measured in the laboratory
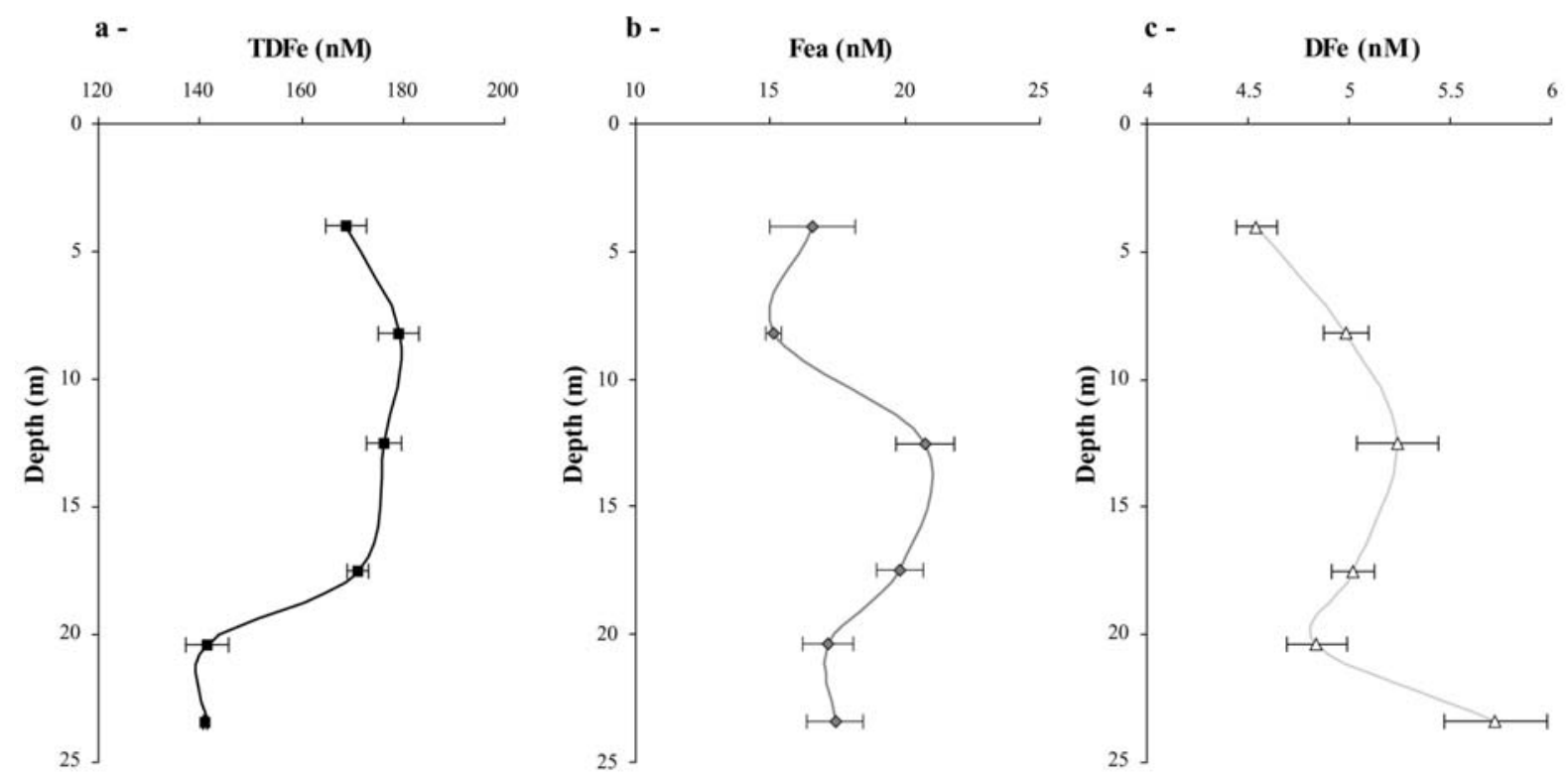

\section{Acknowledgements}

We are grateful to INSU for providing the submersible analyser and the N/O Côtes de la Manche. K.Okamura and an anonymous reviewer are acknowledged for their useful comments. We thank Mickaël Roudaut, Lionel Scouarnec, Christophe Guillerm and Pierre Karleskind for technical assistance. Monique Briand and Robert Marc are acknowledged for their work on the illustrations. Contribution $\mathrm{N}^{\circ} \operatorname{xxxxxxx}$ of the IUEM, European Institute for Marine Studies (Brest, France) 


\section{References}

Blain, S., Jannasch, H.W. and Johnson, K., 2000. In situ chemical analysers with colorimetric detection. In: M.V. Edt (Editor), Chemical sensor in oceanography. Gordon and Breach Sciences Publishers OPA Ltd., pp. 49-70.

Bowie, A.R. et al., 2003. Shipboard analytical intercomparison of dissolved iron in surface waters along a North-South transect of the Atlantic Ocean. Mar. Chem., 84: 19-34.

Bruland, K.W., Francks, R.P., Knauer, G.A. and Martin, J.H., 1979. Sampling and analytical method for the determination of Copper, Cadmium, Zinc, and Nickel at the nanogram per liter level in seawater. Anal. Chim. Acta, 105: 233-245.

Chapin, T.P., Jannasch, H.W. and Johnson, K.S., 2002. In situ osmotic analyser for the year-long continuous determination of Fe in hydrothermal systems. Anal.Chim.Acta, 463.

Chin, C.S. et al., 1994. In situ observations of dissolved iron and manganese in hydrothermal vent plumes, Juan de Fuca Ridge. J. Geophys. Res., 99, NB3: 4969-4984.

Chin, C.S., Johnson, K.S. and Coale, K.H., 1992. Spectrophotometric determination of dissolved manganese in natural waters with 1-(2-pyridylazo)-2-naphthol : application to analysis in situ in hydrothermal plumes. Mar. Chem., 37: 65-82.

Coale, K.H., Chin, C.S., Massoth, G.J., Johnson, K.S. and Baker, E.T., 1991. In situ chemical mapping of dissolved iron and manganese in hydrothermal plumes. Nature, 352: 325-328.

Daniel, A. et al., 1995a. A submersible flow-injection analyser for in situ determination of nitrite and nitrate in coastal waters. Mar. Chem., 51: 67-78.

Daniel, A., Birot, D., Lehaitre, M. and Poncin, J., 1995b. Characterization and reduction of interferences in flow-injection analysis for the in situ determination of nitrate and nitrite in sea water. Anal. Chim. Acta, 308: 413-424.

de Baar, H.J.W. et al., 1999. Low dissolved Fe and the absence of diatom blooms in remote Pacific waters of the Southern Ocean. Mar. Chem., 66: 1-34.

de Baar, H.J.W. and de Jong, J.T.M., 2001. Distributions, sources and sinks of iron in seawater. In: D.R. Turner and K.A. Hunter (Editors), Biogeochemistry of Fe in Seawater. SCOR/IUPAC, pp. 123-253.

Dierssen, H., Balzer, W. and Landing, W.M., 2001. Simplified synthesis of an 8-hydroxyquinoline chelating resin and a study of trace metal profiles from Jellyfish Lake, Palau. Mar. Chem., 73: 173-192.

Floch, J., Blain, S., Birot, D. and Treguer, P., 1998. In situ determination of silicic acid in sea water based on FIA and colorimetric dual-wavelength measurements. Anal. Chim. Acta, 377: 157-166.

Gamo, T., Sakai, H., Nakayama, E., Ishida, K. and Kimoto, H., 1994. A submersible flow-through analyser for in situ colorimetric measurement down to $2000 \mathrm{~m}$ depth in the ocean. Anal. Sci., 10: 843-850.

Johnson, K.S., Beehler, C.L. and Sakamoto, C.M., 1986a. A submersible flow analysis system. Anal.Chim.Acta, 179: 245-257.

Johnson, K.S., Beehler, C.L., Sakamoto-Arnold, C.M. and Childress, J.J., 1986b. In situ measurements of chemical distributions in a deep-sea hydrothermal vent field. Nature, 231: 1139-1141.

Johnson, K.S. and Coletti, L.J., 2002. In situ ultraviolet spectrophotometry for high resolution and long term monitoring of nitrate, bromide and bisulfide in the ocean. Deep-Sea Res. Part I, 49(7): 1291-1305.

Le Bris, N., Sarradin, P.-M., Birot, D. and Alayse-Danet, A.-M., 2000. A new chemical analyzer for in situ measurement of nitrate and total sulfide over hydrothermal vent biological communities. Mar. Chem., 72: 1-15.

Massoth, G.J. et al., 1998. Manganese and iron in hydrothermal plumes resulting from the 1996 Gorda Ridge Event. Deep Sea Res. II, 45: 2683-2712.

Massoth, G.J. et al., 1995. Observations of manganese and iron at the coaxial seafloor eruption site, Juan de Fuca Ridge. Geophys. Res. Lett., 22, N²: 151-154.

Measures, C.I., Yuan, J. and Resing, J.A., 1995. Determination of iron in seawater by flow injection analysis using in-line preconcentration and spectrophotometric detection. Mar. Chem., 50: 3-12.

Obata, H., Karatani, H., Matsui, M. and Nakayama, E., 1997. Fundamental studies for chemical speciation of iron in seawater with an improved analytical method. Mar. Chem., 56: 97-106.

Obata, H., Karatani, H. and Nakayama, E., 1993. Automated determination of iron in seawater by chelating resin concentration and chemiluminescence detection. Anal. Chem., 65: 1524-1528.

Okamura, K. et al., 2001. Development of a deep in situ Mn analyzer and its application for hydrothermal plume observation. Mar. Chem., 76: 17-26.

Riemers, C.E. and Glud, R.N., 2000. Chemical sensors in oceanography. in: M.S. Varney (ed), Gordon and Beach, Amsterdam.

Sarradin, P.M., Le Bris, N., Birot, D. and Caprais, J.-C., 1999. Laboratory adaptation of the methylene blue method to flow injection analysis: towards in situ sulfide analysis in hydrothermal seawater. Anal. Commun., 36: 157-160. 
Weeks, D.A. and Bruland, K.W., 2002. Improved method for shipboard determination of iron in seawater by flow injection analysis. Anal. Chim. Acta, 453: 21-32. 